Article

\title{
Effect of Fructose and Ascorbic Acid on the Performance of Cross-Linked Fish Gelatin Films
}

\author{
Pedro Guerrero ${ }^{1, *}$, Iraitz Zugasti ${ }^{1}$, Alaitz Etxabide ${ }^{2}$, Huynh Nguyen Duy Bao ${ }^{3}{ }^{(D)}$, \\ Trung Trang $\mathrm{Si}^{3}$, Miriam Peñalba ${ }^{1}$ and Koro de la Caba ${ }^{1, *(1)}$ \\ 1 BIOMAT Research Group, University of the Basque Country (UPV/EHU), Escuela de Ingeniería de \\ Gipuzkoa, Plaza de Europa 1, 20018 Donostia-San Sebastián, Spain; iraitz.zugasti@ehu.eus (I.Z.); \\ miriam.penalba@ehu.eus (M.P.) \\ 2 ALITEC, Public University of Navarra, Department of Agronomy, Biotechnology and Food, \\ Campus Arrosadia s/n, 31006 Pamplona-Iruña, Spain; alaitz.etxabide@unavarra.es \\ 3 Faculty of Food Technology, Nha Trang University, 02 Nguyen Dinh Chieu Street, Nha Trang City 650000, \\ Vietnam; hndbao@ntu.edu.vn (H.N.D.B.); trungts@ntu.edu.vn (T.T.S.) \\ * Correspondence: pedromanuel.guerrero@ehu.es (P.G.); koro.delacaba@ehu.es (K.d.l.C.)
}

Received: 8 February 2020; Accepted: 28 February 2020; Published: 4 March 2020

check for updates

\begin{abstract}
Gelatin was extracted from fish scales in this work, in an attempt to valorise abundant and available fishery by-products as an approach towards a more circular economy. With this strategy in mind, fish scale gelatin was used to prepare active films. In this regard, the development of advanced materials from gelatin involves its modification to enhance functional properties, particularly barrier properties, to achieve the requirements for specific value-added purposes, such as food or pharmaceutical/biomedical applications. The improvement of those functional properties can be achieved by means of chemical cross-linking processes. In this context, non-enzymatic reactions were carried out with the addition of fructose and ascorbic acid into gelatin film forming formulations, and cross-linking was induced by a heat-treatment. These cross-linking reactions resulted in higher barrier features, especially for those films prepared with ascorbic acid.
\end{abstract}

Keywords: fish gelatin; fructose; ascorbic acid; cross-linking; antioxidant

\section{Introduction}

A substantial part of plastic comes from packaging applications and it is produced from fossil fuels, finite and non-renewable resources. In this scenario, the abundance of bio-waste converts this material into an environmentally friendly option to be exploited as biodegradable and renewable materials [1]. Among them, proteins and polysaccharides have been investigated to develop new biodegradable films due to their abundance, renewable character and film forming ability [2]. In particular, gelatin derived from connective tissues, skin and bones of pig, bovine and fish is getting considerable demand in the last years for applications such as active food packaging and controlled release of bioactive compounds.

Considering that the global fish production peaked at about 171 million tons in 2016 [3], fishery wastes could be an important source of gelatin to develop new materials, reduce food-industry wastes and improve their management, as well as to decrease the use of synthetic plastic products. Currently, the major exporters of fish and fish products, after China, are Norway, Vietnam and Thailand [4]. Particularly, Vietnam produces about 7 million tons of fish per year [5], involving a high quantity of fish wastes, which are rich in collagen and can be used to extract gelatin through acid (type A gelatin) or alkali (type B gelatin) hydrolysis [6]. The amino acid composition of gelatin is similar to that of collagen, containing predominantly proline (Pro) and hydroxyproline (Hyp). In general, the imino acid content (Pro + Hyp) in cold-water fish gelatins is lower than in mammalian gelatins and, thus, 
they show a lower melting point, which could be a benefit for the manufacture of fish gelatin-based products [7].

Gelatin shows some functional properties, such as biocompatibility, film forming ability and biodegradability, that promote its application for food packaging, pharmaceutical and biomedical purposes. However, due to its hydrophilic nature, gelatin-based films exhibit high brittleness and water sensitivity. Therefore, the improvement of those properties must be addressed by means of physical, chemical or enzymatic processes [6]. In this work, non-enzymatic reactions were carried out by adding fructose or ascorbic acid into gelatin film forming formulations and cross-linking was induced by a heat-treatment [8-10].

Fructose and ascorbic acid can undergo non-enzymatic reactions, such as Maillard reaction, which involve a series of reactions of the carbonyl group with amino group-containing residues in gelatin, mainly lysine, arginine and histidine [11]. The initial stage of the Maillard reaction with fructose is similar to that with glucose, the carbonyl group of fructose and the $\varepsilon$-amino group of lysine in gelatin react to form a Schiff base, which is isomerized to fructosylamine, resulting in the formation of new species in a process termed as the Heyns rearrangement [12]. Regarding ascorbic acid, in the first stage, 3-deoxy-3-(alkylamino)ascorbic is isolated from the substitution reaction between ascorbic acid and the $\varepsilon$-amino group of lysine. Then, dehydroascorbic acid is obtained from the primary oxidation product of ascorbic acid [13,14]. In a second stage, these products are transformed into reactive intermediates that take part in complex reactions, with a final stage of the Maillard reaction where brown compounds, known as melanoidins [15], are obtained. These final products are anionic chromophoric compounds with some relevant functionalities, including antioxidant, antimicrobial, prebiotic, and antihypertensive activities $[10,12,13]$. Additionally, ascorbic acid is widely used as an antioxidant compound, providing the final product with an additional functionality $[16,17]$.

In this work, gelatin was extracted from fish scales and it was used to prepare active films with fructose or ascorbic acid in order to promote non-enzymatic crosslinking and improve the functional properties of the resulting fish gelatin films. Hence, the effect of fructose and ascorbic acid on the performance of cross-linked films was assessed.

\section{Materials and Methods}

\subsection{Materials}

Gelatin extracted from fish scales was kindly supplied from Nha Trang University (Vietnam). Glycerol, purchased from Panreac, was used as plasticizer, while D(-)-fructose (VWR Chemicals $\mathrm{BDH}^{\circledR}$, West Chester, PA, USA) and ascorbic acid (Sigma-Aldrich, Saint Louis, MO, USA) were used as cross-linkers. $1 \mathrm{~N} \mathrm{NaOH}$ (Sigma-Aldrich) was used to adjust $\mathrm{pH}$ during film preparation. Ethanol 96\% (EtOH 96\%) from Sigma-Aldrich was used as fatty simulant for the ascorbic acid release assay. Additionally, $1 \mathrm{M}$ picrylsulfonic acid (2,4,6-trinitrobenzenesulfonic acid, TNBS) solution and anhydrous $\mathrm{NaHCO}_{3}$ (purity $>99.7 \%$ ), purchased from Sigma-Aldrich, and diethyl ether stabilized with 6 ppm of $\mathrm{BHT}$ and $6 \mathrm{~N} \mathrm{HCl}$, supplied by Panreac, were used to measure cross-linking degree.

\subsection{Extraction of Fish Gelatin}

Fresh seabass (Lates calcarifer) scales were obtained from Danh Tuyen Co. Ltd. (Nha Trang, Vietnam). The fish scales were packed in polyethylene bags, iced, and quickly transported to the laboratory of Nha Trang University. Then, the fish scales were washed by rinsing with tap water to remove superfluous materials and packed in zip lock plastic bags (500 g/bag). The bags were kept at $-20 \pm 2{ }^{\circ} \mathrm{C}$ until use for gelatin extraction.

Fish scales were immersed and stirred with $5 \% \mathrm{NaCl}$ solution $(1 / 10, w / v)$ for $30 \mathrm{~min}$ at room temperature; this step was repeated twice. The scales were then treated with 10 volumes $(w / v)$ of $0.4 \%$ $\mathrm{NaOH}$ solution at room temperature for $4 \mathrm{~h}$ to remove the non-collagen proteins. After the alkali treatment, the scales were neutralized by washing under running tap water. Subsequently, the scales 
were treated with 10 volumes $(w / v)$ of $0.4 \% \mathrm{HCl}$ solution at room temperature for $4 \mathrm{~h}$ to remove the minerals. After acid treatment, the scales were neutralized by washing under running tap water and then subjected to a final wash with distilled water. Gelatin was extracted in distilled water at $70{ }^{\circ} \mathrm{C}$ for $1.5 \mathrm{~h}$. The ratio of the scales to distilled water was 1:1 (w/v). The coarse solids were filtered out with a filter cloth and the filtrate was then vacuum-filtered with a Whatman No. 1 filter paper. The gelatin solution (vacuum-filtrate) was vacuum-dried in inox trays at $55^{\circ} \mathrm{C}$ until dried thin films were formed. The yield of gelatin extracted was $13.2 \pm 2.3 \%$.

\subsection{Characterization of Fish Gelatin}

Gel strength was determined using a model CR-500DX Sun Rheometer (Tokyo, Japan) according to the method described in Gelatin Manufacturers Institute of America [18]. Briefly, gelatin was dissolved in distilled water at $60{ }^{\circ} \mathrm{C}$ to obtain the final concentration of $6.67 \%(w / v)$. Gelatin solution was placed in a Bloom jar (capacity of 150-155 mL, overall height of $85 \mathrm{~mm}$, inside diameter of $59 \mathrm{~mm}$, outside diameter of $66 \mathrm{~mm}$, neck inside diameter of $41 \mathrm{~mm}$, shoulder height of $65 \mathrm{~mm}$ ), and then cooled in a refrigerator at $10.0 \pm 0.1^{\circ} \mathrm{C}$ for $16-18 \mathrm{~h}$. The gel strength was determined on the rheometer with a cell load of $10 \mathrm{~N}$, test speed of $0.5 \mathrm{~mm} / \mathrm{s}$, stroke displacement of $4 \mathrm{~mm}$, and surface detection of $1 \mathrm{~g}$.

Odour of gelatin was determined according to the sensory evaluation method of Muyonga et al. [19] using a five-member panel. Briefly, gelatin was dissolved in distilled water at $50{ }^{\circ} \mathrm{C}$ in test tubes with screw caps to obtain the final concentration of $6.67 \%(w / v)$. The test tubes were held in a water bath at $50{ }^{\circ} \mathrm{C}$, with the screw caps lightly closed. Panelists were trained to assess according to a scale from 0 to 5 , in which $0=$ odourless; $1=$ very mild and only perceivable on careful assessment; $2=$ mild but easily perceivable; $3=$ strong but not offensive; $4=$ strong and offensive; $5=$ very strong and very offensive.

Clarity of gelatin solution was determined by the method described in Gelatin Manufacturers Institute of America [18]. Briefly, gelatin was dissolved in distilled water at $65^{\circ} \mathrm{C}$ for $10-15 \mathrm{~min}$ to obtain a $6.67 \%$ gelatin solution in $150 \mathrm{~mL}$ beakers. The beakers were held in a $45^{\circ} \mathrm{C}$ water bath until sample temperature was $45 \pm 1^{\circ} \mathrm{C}$. The clarity of a $6.67 \%$ gelatin solution was determined at $45^{\circ} \mathrm{C}$ by measuring the transmittance percent through a $1 \mathrm{~cm}$ cuvette at $620 \mathrm{~nm}$ using a model 550 Biochrom Libra spectrophotometer.

Moisture and ash contents of the vacuum-dried gelatin were determined using AOAC official methods number 934.01 and 942.05, respectively [20].

Quantitative and qualitative analysis of free amino acid was performed with a Biochrom $30+$ amino acid analyzer physiological system (Bonsai lab, Biochrom, UK).

Fourier transform infrared (FTIR) spectroscopy was carried out by using a Nicolet Nexus FTIR spectrometer equipped with a thermoelectric cell holder and a horizontal attenuated total reflectance (ATR) crystal (ZnSe). The samples were placed directly onto the ATR crystal and spectra were collected in transmittance mode at room temperature. Each spectrum was the result of the average of 32 scans at $4 \mathrm{~cm}^{-1}$ resolution. Measurements were recorded in the wavelength range of $4000-800 \mathrm{~cm}^{-1}$. All spectra were smoothed using the Savitzky-Golay function. Second-derivative spectra of the amide region were used at peak position guides for the curve fitting procedure, using OriginPro 9.1 software.

\subsection{Film Preparationc}

Firstly, $2.5 \mathrm{~g}$ of gelatin and the corresponding amount of fructose or ascorbic acid to reach $10 \mathrm{wt} . \%$ and $20 \mathrm{wt} . \%$ (on gelatin dry basis) were dissolved in $50 \mathrm{~mL}$ of distilled water for $30 \mathrm{~min}$ at $80^{\circ} \mathrm{C}$ under continuous stirring. After that, $\mathrm{pH}$ was adjusted to 7 with $1 \mathrm{~N} \mathrm{NaOH}$ and then, $10 \mathrm{wt}$.\% glycerol (on gelatin dry basis) was added to the solution, which was maintained at $80{ }^{\circ} \mathrm{C}$ for other 30 min under stirring with a final adjustment of $\mathrm{pH}$ to 7 . Afterwards, $10 \mathrm{~g}$ of film forming solution were poured onto Petri dishes ( $8.6 \mathrm{~mm}$ diameter) and left to dry $48 \mathrm{~h}$ at room temperature to evaporate water and form the film. After that, films were heated at $70{ }^{\circ} \mathrm{C}$ for $24 \mathrm{~h}$ and named as $10 \mathrm{~F}$ and $20 \mathrm{~F}$ for the films with $10 \mathrm{wt} . \%$ and $20 \mathrm{wt} . \%$ of fructose, and 10AA and 20AA for the films with $10 \mathrm{wt} . \%$ and $20 \mathrm{wt} . \%$ of ascorbic acid. Films without fructose and without ascorbic acid, cured at $70{ }^{\circ} \mathrm{C}$, were used as control 
films. Finally, all films were kept in a controlled bio-chamber (ACS Sunrise $700 \mathrm{~V}$ ) at $25^{\circ} \mathrm{C}$ and $50 \%$ relative humidity. Film thickness was measured to the nearest $0.080 \mathrm{~mm}$ with a handheld QuantuMike digimatic micrometer (Mitutoyo). Three measurements at different positions were taken from seven specimens for each composition. The calculated average thickness was $0.080 \pm 0.002 \mathrm{~mm}$.

\subsection{Assessment of Cross-linking Extension}

UV-vis spectroscopy was used to measure light absorption in the UV-vis range (200-800 nm) using a V-630 UV-vis spectrophotometer (Jasco).

The cross-linking extent was measured according to the method of Panzavolta et al. [21]. Briefly, an UV assay of uncross-linked amino groups was performed on thermally treated films and on non-cured films as reference. After the reaction with $0.5 \%$ TNBS, gelatin was hydrolysed with $\mathrm{HCl}$ $(6 \mathrm{M})$ and extracted with diethyl ether. The solution absorbance was measured against a blank by $\mathrm{UV}$-vis spectroscopy at a wavelength of $346 \mathrm{~nm}$. The moles of free amino groups per gram of gelatin were calculated by the following equation:

$$
\left[\mathrm{NH}_{2}\right]=\frac{(2 \times A \times B)}{(\varepsilon \times b \times x)}
$$

where $\mathrm{A}$ is the sample absorbance, $\mathrm{B}$ is the final sample volume (L), $\varepsilon$ is the molar absorptivity of TNP-lys, (precisely $1.46 \times 10^{4} \mathrm{~L} \cdot \mathrm{mol}^{-1} \cdot \mathrm{cm}^{-1}$ ), $\mathrm{b}$ is the cell path length $(\mathrm{cm})$, and $x$ is the sample weight $(\mathrm{g})$.

The obtained values of free $\varepsilon$-amino groups/gelatin ratio were employed to calculate the cross-linking extent (CE) equation:

$$
C E(\%)=\left(\frac{\left[\mathrm{NH}_{2}\right]_{g}-\left[\mathrm{NH}_{2}\right]_{n f}}{\left[\mathrm{NH}_{2}\right]_{g}}\right) 100
$$

where $g$ denotes the non-reacted gelatin used as reference and $\mathrm{nf}$ the reacted gelatin.

\subsection{Characterization of Gelatin Films}

Colour parameters $\left(\mathrm{L}^{*}, \mathrm{a}^{*}, \mathrm{~b}^{*}\right)$ were determined using a CR-400 Minolta Chroma-Meter colourimeter (Konica Minolta). Films were placed on the surface of a white standard plate (calibration plate values: $\left.\mathrm{L}^{*}=97.39, \mathrm{a}^{*}=0.03, \mathrm{~b}^{*}=1.77\right)$ and colour parameters were measured using the CIELAB colour scale: $\mathrm{L}^{*}=0$ (black) to $\mathrm{L}^{*}=100$ (white), $-\mathrm{a}^{*}$ (greenness) to $+\mathrm{a}^{*}$ (redness), and $-\mathrm{b}^{*}$ (blueness) to $+\mathrm{b}^{*}$ (yellowness). Colour difference $\left(\Delta \mathrm{E}^{*}\right)$ was calculated referred to the non-cured film:

$$
\Delta E^{*}=\sqrt{\left(\Delta L^{*}\right)^{2}+\left(\Delta a^{*}\right)^{2}+\left(\Delta b^{*}\right)^{2}}
$$

The browning index (BI) was used as an indicator of brown color intensity during cross-linking process and it was calculated as follows:

$$
B I(\%)=\left(\frac{x-0.31}{0.172}\right) 100
$$

where,

$$
x=\frac{\left(a^{*}+1.75 L^{*}\right)}{\left(5.645 L^{*}+a^{*}-3.012 b^{*}\right)}
$$

The mechanical properties of fish gelatin films were analyzed using an Insight 10 Electromechanical Testing System (MTS Systems), equipped with a tensile load cell of $250 \mathrm{~N}$. Tensile strength (TS) and elongation at break (EB) were determined according to ASTM D1708-13 [22]. The crosshead speed was 
set at $1 \mathrm{~mm} / \mathrm{min}$ and samples with $22.25 \mathrm{~mm}$ length and $4.75 \mathrm{~mm}$ width were used. Seven samples were tested for each composition.

The ascorbic acid release was determined at room temperature for 4 days by immersion of three samples $(1.5 \mathrm{~cm} \times 2.0 \mathrm{~cm})$ of each composition into a EtOH $96 \%$ solution $(8 \mathrm{~mL})$, used as fatty food simulant. Films were immersed into dark glass vessels to protect the antioxidant compounds from light. UV-vis spectroscopy (V-630 UV-Jasco Spectrophotometer, Jasco, Madrid, Spain) was employed to measure light absorption from 200 to $800 \mathrm{~nm}$. The absorption spectra of the solutions were recorded after $0.5,1,2,24,48,72$ and $96 \mathrm{~h}$.

\subsection{Statistical Analysis}

Analysis of variance (ANOVA) was used to determine the significance of differences among samples. The analysis was performed with a SPSS computer program (SPSS Statistic 25.0) and Tukey's test was used for multiple comparisons. Differences were statistically significant at the $P<0.05$ level.

\section{Results and Discussion}

\subsection{Characterization of Fish Gelatin}

Fish gelatin showed a gel strength of $223.50 \pm 0.71 \mathrm{~g}$, an odour value of $1.53 \pm 0.21$ (odourless $=0$; very strong odour $=5$ ), and a clarity value of $95.05 \pm 4.26 \%$. Additionally, fish gelatin had a moisture content of $8.37 \pm 0.35 \%$ and an ash content of $1.06 \pm 0.11 \%$. Furthermore, the amino acid composition was determined by elemental analysis and it is shown in Table 1 . Glycine $(33.15 \%)$, alanine $(13.58 \%)$, proline $(11.13 \%)$, and hidroxyproline $(8.55 \%)$ were the most abundant amino acids present in the extracted gelatin, while the lowest amounts were found for tyrosine $(0.50 \%)$, histidine $(0.52 \%)$, and isoleucine $(0.76 \%)$. The relative high content of proline and hydroxiproline is related to the stability of the triple helical structure in renatured gelatin. In particular, hydroxyproline is suggested to play a role as stabilizer of the triple-stranded collagen helix due to its hydrogen bonding ability through its hydroxyl group [23]. The amino acid concentrations determined in this work were similar to the ones obtained by Santos et al. [24].

Table 1. Amino acid content of fish gelatin expressed as number of residues per 100 residues.

\begin{tabular}{cc}
\hline Amino Acids & Concentration (\%) \\
\hline Hydroxyproline & 8.55 \\
Aspartic acid & 4.28 \\
Threonine & 2.19 \\
Serine & 2.85 \\
Glutamic acid & 7.16 \\
Proline & 11.13 \\
Glycine & 33.15 \\
Alanine & 13.58 \\
Valine & 1.77 \\
Methionine & 1.36 \\
Isoleucine & 0.76 \\
Leucine & 1.73 \\
Tyrosine & 0.50 \\
Phenylalanine & 1.52 \\
Histidine & 0.52 \\
Lysine & 2.62 \\
Arginine & 4.96 \\
\hline
\end{tabular}

The effect of the extraction treatment in protein structure was studied by ATR-FTIR and the spectrum of extracted gelatin is shown in Figure 1a. As can be observed, the main absorption bands of gelatin were related to $\mathrm{C}=\mathrm{O}$ stretching at $1630 \mathrm{~cm}^{-1}$ (amide I), $\mathrm{N}-\mathrm{H}$ stretching at $1530 \mathrm{~cm}^{-1}$ (amide II) and $\mathrm{C}-\mathrm{N}$ stretching at $1230 \mathrm{~cm}^{-1}$ (amide III) [8,25]. 

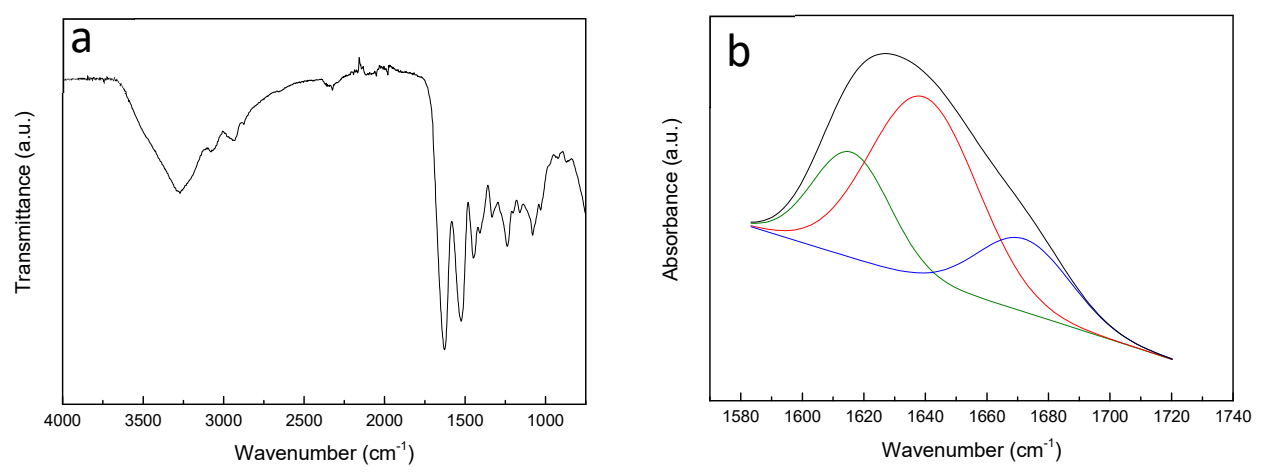

Figure 1. (a) FTIR spectra of fish scale gelatin and (b) curve fitting spectra of amide I.

Gelatin is a semi-crystalline biopolymer with both crystalline and amorphous phases. The crystalline phase consists of triple helixes and bundles of triple helixes of denatured collagen, whereas the amorphous phase is composed of colloidal chains which form simple helixes due to the high content of proline, responsible for protein chain turns [26-28]. Therefore, in order to assess the secondary structure of the extracted fish gelatin, curve fitting of amide I band was carried out (Figure $1 \mathrm{~b}$ ). The absorbances at $1615.92,1642.36$, and $1675.06 \mathrm{~cm}^{-1}$ are assigned to $\beta$-sheet, $\alpha$-helix/random coil, and $\beta$-turn conformations, respectively [8]. From the analysis of Figure $1 b$, it was found that the secondary structure of gelatin consisted mainly of $\alpha$-helix/random coil conformation (56.87\%), while $\beta$-sheet (23.44\%) and $\beta$-turn (19.70\%) conformations were present to a lesser extent.

\subsection{Assessment of Cross-linking Extension}

It is generally agreed that the rate of non-enzymatic reactions increases at temperatures over $55^{\circ} \mathrm{C}$ and, therefore, most of the studies dealing with these reactions are carried at temperatures higher than $55^{\circ} \mathrm{C}$, with a significant enhancement of the cross-linking extension as heating temperature increases $[10,29,30]$. Taking this into account, a preliminary characterization was carried out by UV-vis spectroscopy (data not shown) in order to establish an appropriate heating temperature to promote the cross-linking reaction. In this study, the temperature selected was $70^{\circ} \mathrm{C}$.

UV-vis spectroscopy was used to study the reaction extension as a function of the type of cross-linker (fructose or ascarbic acid) and their content (10 and $20 \mathrm{wt} . \%)$. As shown in Figure 2, fish gelatin films (control) reveled high absorption of UV light due to the presence of peptide bonds (200-250 nm) and aromatic amino acids (250-300 nm), such as tyrosine and phenylalanine [31]. Regarding the cross-linker addition and subsquent heat-treatment, an absorbance increase was shown, irrespective of the type of cross-linker. As the increase in UV light absorbance is often used as a measurement of cross-linking extension, the high absorption at 300-420 nm would be indicative of the reaction between gelatin and the cross-linkers used in this work [32]. Taking this into account, it can be said that fructose-cross-linked films showed lower cross-linking extension than gelatin films cross-linked with ascorbic acid, since lower absorbance values were found for fructose-added films. Furthermore, these results indicated that higher cross-linker amount induced a more extensive cross-linking reaction. It is worth noting that all cross-linked films presented excellent UV light barrier properties, which could prevent undesirable oxidation reactions, for instance, in food products. 


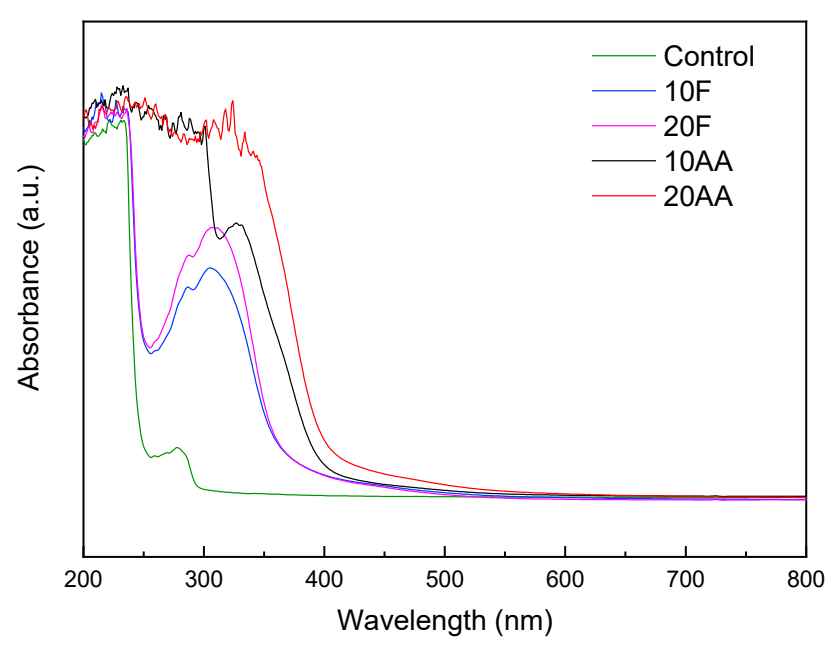

Figure 2. UV-vis spectra of fish gelatin films as a function of cross-linker type and content.

In order to support the previous results, TNBS method was used to determine quantitatively the degree of cross-linking in the films containing different contents of fructose or ascorbic acid and values are summarized in Table 2. Results indicated that gelatin was glycated by fructose and ascorbic acid, as previously shown by UV spectroscopy. As can be seen in Table 2, a higher cross-linker content led to a higher reaction extension for both cross-linkers. Although the reaction extension was not significantly $(P>0.05)$ different for the films cross-linked with $10 \mathrm{wt} . \%$ fructose or ascorbic acid, the highest cross-linking extension was found for the films cross-linked with $20 \mathrm{wt} . \%$ ascorbic acid, in accordance with UV-vis spectra shown in Figure 2.

Table 2. Cross-linking extension (CE) of gelatin films as a function of cross-linker type and content.

\begin{tabular}{cc}
\hline Film & CE (\%) \\
\hline $10 \mathrm{~F}$ & $37.58 \pm 0.48^{\mathrm{a}}$ \\
20F & $59.72 \pm 1.12^{\mathrm{b}}$ \\
$10 \mathrm{AA}$ & $37.88 \pm 1.32^{\mathrm{a}}$ \\
$20 \mathrm{AA}$ & $65.62 \pm 1.15^{\mathrm{c}}$
\end{tabular}

a-c Two means followed by the same letter in the same column are not significantly $(P>0.05)$ different through the Tukey's multiple range test.

\subsection{Characterization of Gelatin Films}

The colour change that takes place in the cross-linked films after heating can be considered as an indicator of the cross-linking reaction. Therefore, the reaction extension between gelatin and fructose or ascorbic acid was evaluated according to the colour change that took place in the films after the heating treatment (Figure 3). 


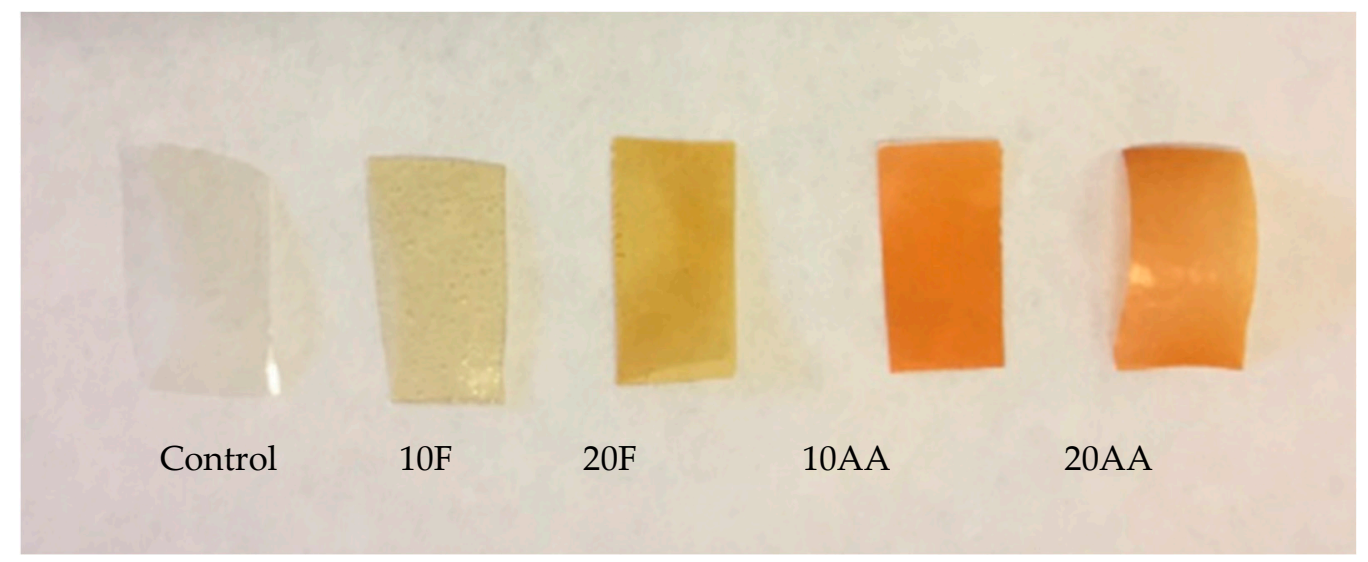

Figure 3. Colour change of fish gelatin films as a function of cross-linker type and content.

Additionally, colour parameters were measured according to CIELab scale and values are shown in Table 3. The addition of cross-linkers caused a decrease in $L^{*}$ and $a^{*}$ values, while $b^{*}$ value increased and, consequently, total colour difference $\left(\Delta \mathrm{E}^{*}\right)$ significantly $(P<0.05)$ increased in all samples but, especially, in fish gelatin films with 20 wt.\% ascorbic acid, indicating that ascorbic acid induced a higher extension of the reaction than fructose, as shown by CE values in Table 2.

Due to the formation of brown-coloured products in the final stage of cross-linking reactions, the browning index (BI) was calculated to study the extension of the reactions. As can be seen in Table 3, both cross-linkers induced browning, irrespective of type and content. However, ascorbic acid-cross-linked films presented significantly $(P<0.05)$ higher values of BI, especially those films prepared with $20 \%$ of ascorbic acid, suggesting that a higher amount of brown-coloured products was formed and so, indicating that ascorbic acid promoted a more extended cross-linking than fructose.

Table 3. CIELab parameters $\left(\mathrm{L}^{*}, \mathrm{a}^{*}, \mathrm{~b}^{*}\right)$, total colour difference $\left(\Delta \mathrm{E}^{*}\right)$ and brown index $(\mathrm{BI})$ for gelatin films as a function of cross-linker type and content.

\begin{tabular}{cccccc}
\hline Film & $\mathbf{L}^{*}$ & $\mathbf{a}^{*}$ & $\mathbf{b}^{*}$ & $\Delta \mathbf{E}^{*}$ & BI (\%) \\
\hline Control & $95.422 \pm 0.285^{\mathrm{a}}$ & $-0.001 \pm 0.050^{\mathrm{a}}$ & $3.041 \pm 0.181^{\mathrm{a}}$ & - & - \\
10F & $92.742 \pm 0.484^{\mathrm{b}}$ & $-2.138 \pm 0.116^{\mathrm{b}}$ & $20.406 \pm 1.696^{\mathrm{b}}$ & $17.705 \pm 1.735^{\mathrm{a}}$ & $22.261 \pm 2.329^{\mathrm{a}}$ \\
20F & $91.252 \pm 0.887^{\mathrm{c}}$ & $-1.759 \pm 0.513^{\mathrm{c}}$ & $31.657 \pm 3.208^{\mathrm{c}}$ & $28.986 \pm 3.208^{\mathrm{b}}$ & $39.602 \pm 5.711^{\mathrm{b}}$ \\
10AA & $90.642 \pm 0.492^{\mathrm{c}}$ & $-1.510 \pm 0.174^{\mathrm{c}}$ & $31.507 \pm 1.719^{\mathrm{c}}$ & $28.910 \pm 3.253^{\mathrm{b}}$ & $39.788 \pm 3.188^{\mathrm{b}}$ \\
20AA & $88.835 \pm 0.653^{\mathrm{d}}$ & $-0.800 \pm 0.327^{\mathrm{d}}$ & $39.546 \pm 2.248^{\mathrm{d}}$ & $37.105 \pm 2.315^{\mathrm{c}}$ & $55.547 \pm 5.008^{\mathrm{c}}$ \\
\hline
\end{tabular}

${ }^{a-d}$ Two means followed by the same letter in the same column are not significantly $(P>0.05)$ different through the Tukey's multiple range test.

Once the cross-linking extension was indirectly and directly analyzed as a function of cross-linker type and content, mechanical properties were measured in order to assess the effect of cross-linking on the film performance. Hence, mechanical behaviour was evaluated, and tensile strength (TS) and elongation at break (EB) values of fish gelatin films are shown in Table 4. It is well known that the mechanical properties depend on the interactions between the components [33-35]. Therefore, TS values significantly $(P<0.05)$ increased with the incorporation of $10 \mathrm{wt} . \%$ fructose or ascorbic acid due to the cross-linking reaction; however, a TS decrease was observed from 10 to $20 \mathrm{wt}$. \% of cross-linker, probably due to a higher content of water formed during cross-linking reaction. Since water acts as a plasticizer, TS decreased but EB significantly $(P<0.05)$ increased, especially for those gelatin films cross-linked with $20 \mathrm{wt}$.\% of ascorbic acid, the films that showed the highest cross-linking extension. 
Table 4. Tensile strength (TS) and elongation at break (EB) of gelatin films as a function of cross-linker type and content.

\begin{tabular}{ccc}
\hline Film & TS $\mathbf{( M P a )}$ & EB (\%) \\
\hline Control & $71.78 \pm 3.82^{\mathrm{a}}$ & $5.14 \pm 0.17^{\mathrm{a}}$ \\
$10 \mathrm{~F}$ & $78.62 \pm 4.74^{\mathrm{b}}$ & $5.24 \pm 0.89^{\mathrm{a}}$ \\
20F & $59.74 \pm 2.88^{\mathrm{c}}$ & $10.23 \pm 0.46^{\mathrm{c}}$ \\
10AA & $77.19 \pm 4.10^{\mathrm{a}, \mathrm{b}}$ & $7.93 \pm 0.54^{\mathrm{b}}$ \\
20AA & $54.25 \pm 3.28^{\mathrm{c}}$ & $19.18 \pm 0.88^{\mathrm{d}}$ \\
\hline
\end{tabular}

a-d Two means followed by the same letter in the same column are not significantly $(P>0.05)$ different through the Tukey's multiple range test.

Finally, the release of ascorbic acid from fish gelatin films was measured. As can be seen in Figure 4, the release was higher for the films with $10 \mathrm{wt.} \%$ of ascorbic acid, in accordance with a lower cross-linking extension and, thus, a higher amount of free ascorbic acid that can migrate from the film into the fatty food simulant. Additionally, since a higher cross-linking extent is usually related to a more compact structure [36], this hinders the antioxidant release, as observed for the films with $20 \mathrm{wt} . \%$ of ascorbic acid.

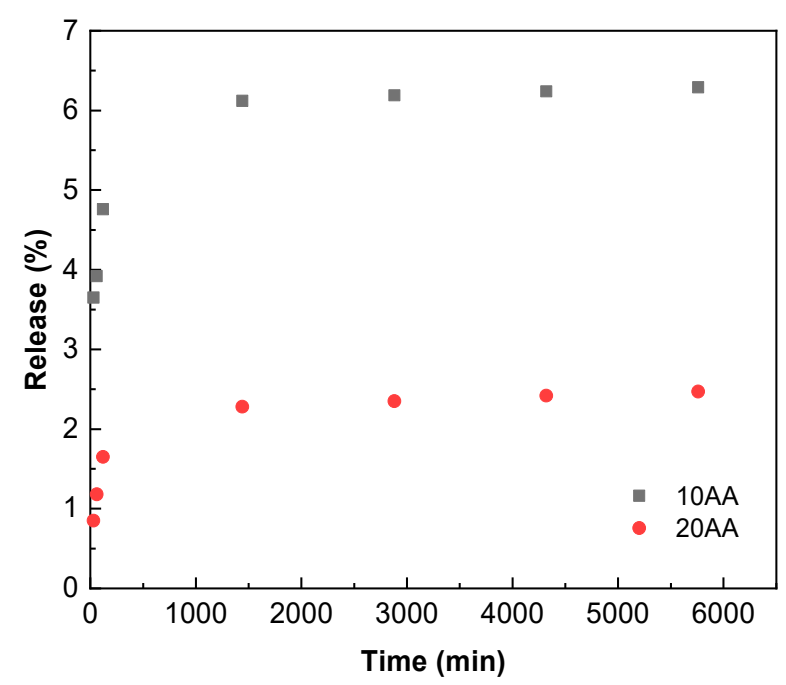

Figure 4. Release of ascorbic acid from gelatin films as a function of acid content and immersion time.

\section{Conclusions}

Fish gelatin films prepared with 10 and $20 \mathrm{wt} . \%$ of fructose or ascorbic acid were homogeneous and transparent. After a heating treatment at $70{ }^{\circ} \mathrm{C}$, a Maillard reaction was promoted and cross-linking extension was assessed by UV-vis spectroscopy, which showed an intense absorbance above $300 \mathrm{~nm}$ related to the formation of brown compounds during cross-linking. In this regard, the films with $20 \mathrm{wt} . \%$ ascorbic acid showed the highest cross-linking extension, as confirmed by the highest $\Delta \mathrm{E}^{*}$ and BI values. Additionally, the formation of water involved in the cross-linking process caused an increase of the film flexibility due to the role of water as plasticizer. Finally, the ascorbic acid release from the films into a fatty simulant was analysed and it was observed that the consumption of the acid in the crosslinking reaction caused a limited antioxidant release.

Author Contributions: Conceptualization, H.N.D.B., T.T.S. and K.d.l.C.; Resources, H.N.D.B., T.T.S, P.G. and K.d.l.C.; Data Curation, H.N.D.B., I.Z. and A.E.; Formal Analysis, P.G., M.P. and K.d.l.C.; Writing-Original Draft Preparation, I.Z. and A.E.; Writing-Review and Editing, H.N.D.B., T.T.S., P.G., M.P. and K.d.l.C.; Supervision, P.G. and K.d.l.C.; Funding Acquisition, K.d.l.C. All authors have read and agreed to the published version of the manuscript. 
Funding: This research was funded by the Ministry of Science, Innovation and Universities (NO. RTI2018097100-B-C22).

Acknowledgments: Alaitz Etxabide thanks the Ministry of Science, Innovation and Universities (Juan de la Cierva contract). Also thanks are due to the Advanced Research Facilities (SGIker) from the UPV/EHU.

Conflicts of Interest: The authors declare no conflict of interest.

\section{References}

1. Xiong, X.; Yu, I.K.M.; Tsang, D.C.W.; Bolan, N.S.; Ok, Y.S.; Igalavithana, A.D.; Kirkham, M.B.; Kim, K.; Vikrant, K. Value-added chemicals from food supply chain wastes: State-of-the-art review and future prospects. Chem. Eng. J. 2019, 375, 121983. [CrossRef]

2. de la Caba, K.; Guerrero, P.; Trung, T.S.; Cruz-Romero, M.; Kerry, J.P.; Fluhr, J.; Maurer, M.; Kruijssen, F.; Albalat, A.; Bunting, S.; et al. From seafood waste to active seafood packaging: An emerging opportunity of the circular economy. J. Clean. Prod. 2019, 208, 86-98. [CrossRef]

3. Ghaly, A.E.; Ramakrishnan, V.V.; Brooks, M.S.; Budge, S.M.; Dave, D. Fish Processing Wastes as a Potential Source of Proteins, Amino Acids and Oils: A Critical Review. J. Microb. Biochem. Technol. 2013, 5, 107-129.

4. Available online: http://www.fao.org/news/archive/news-by-date/2018/en/?Page=2\&ipp=10\&txdynalistpi1\% 5Bpar\%5D=YToxOntzOjE6IkwiO3M6MToiMCI7fQ\%3D\%3D (accessed on 3 March 2020).

5. Available online: http://mseafood.vasep.com.vn/673/onecontent/sector-profiles.htm (accessed on 3 March 2020).

6. Gómez-Guillén, M.C.; Pérez-Mateos, M.; Gómez-Estaca, J.; López-Caballero, E.; Giménez, B.; Montero, P. Fish gelatin: A renewable material for developing active biodegradable films. Trends Food Sci. Technol. 2009, 20, 3-16. [CrossRef]

7. Etxabide, A.; Guerrero, P.; de la Caba, K. A novel approach to manufacture porous biocomposites using extrusion and injection moulding. Eur. Polym. J. 2016, 82, 324-333. [CrossRef]

8. Etxabide, A.; Urdanpilleta, M.; Gómez-Arriaran, I.; de la Caba, K.; Guerrero, P. Effect of pH and lactose on cross-linking extension and structure of fish gelatin fish. React. Funct. Polym. 2017, 117, 140-146. [CrossRef]

9. Kchaou, H.; Benbettaieb, N.; Jridi, M.; Abdelhedi, O.; Karbowiak, T.; Brachais, C.H.; Léonard, M.L.; Debeaufort, F.; Nasri, M. Enhancement of structural, functional and antioxidant properties of fish gelatin films using Maillard reactions. Food Hydrocoll. 2018, 83, 326-339. [CrossRef]

10. Dills, W.L. Protein fructosylation: Fructose the Maillard reaction. Am. J. Clin. Nutr. 1993, 58, 779S-787S. [CrossRef]

11. Pischetsrieder, M. Reaction of L-ascorbic acid with L-arginine derivatives. J. Agric. Food Chem. 1996, 44, 2081-2085. [CrossRef]

12. Schalkwijk, C.G.; Stehouwer, C.D.A.; van Hinsbergh, V.W.M. Fructose-mediated non-enzymatic glycation: Sweet coupling or bad modification. Diabetes Metab. Res. Rev. 2004, 20, 369-382. [CrossRef]

13. Larisch, B.; Gross, U.; Pischetsrieder, M. On the reaction of L-ascorbic acid with propylamine under various conditions: Quantification of the main products by HPLC/DAD. Z Lebensm. Unters. Forsch. A-Food Res. Technol. 1998, 206, 333-337. [CrossRef]

14. Tiller, J.; Berlin, P.; Klemm, D. A novel efficient enzyme-immobilization reaction on $\mathrm{NH}_{2}$ polymers by means of L-ascorbic acid. Biotechnol. Appl. Biochem. 1999, 30, 155-162. [PubMed]

15. Koubaa, M.; Roohinehad, S.; Mungure, T.E.; El-Din, B.A.; Greiner, R.; Mallikarjunan, K. Effect of emerging processing technologies on Maillard reactions. Encycl. Food Chem. 2019, 2, 76-82.

16. Dewhirst, R.A.; Clarkson, G.J.J.; Rothwell, S.D.; Fry, S.C. Novel insights into ascorbate retention and degradation during the washing and post-harvest storage of spinach and other salad leaves. Food Chem. 2017, 233, 237-246. [CrossRef] [PubMed]

17. Nooshkam, M.; Varidi, M.; Bashash, M. The Maillard reaction products as food-born antioxidant and antibrowning agents in model and real food systems. Food Chem. 2019, 275, 644-660. [CrossRef] [PubMed]

18. STANDARD TESTING METHODS FOR EDIBLE GELATIN. Available online: http://www.gelatin-gmia.com/ uploads/1/1/8/4/118450438/gmia_official_methods_2019.pdf (accessed on 3 March 2020).

19. Muyonga, J.H.; Cole, C.G.B.; Duodu, K.G. Extraction and physico-chemical characterisation of Nile perch (Lates niloticus) skin and bone gelatin. Food Hydrocoll. 2004, 581-592. [CrossRef] 
20. Horwitz, W.; Chichilo, P.; Reynolds, H.A. Official methods of analysis of the Association of Official Analytical Chemists. In Official methods of analysis of the Association of Official Analytical Chemists; Horwitz, W., Chichilo, P., Reynolds, H., Eds.; Association of Official Analytical Chemists: Washington, DC, USA, 2000.

21. Panzavolta, S.; Gioffrè, M.; Focarete, M.L.; Gualandi, C.; Foroni, L.; Bigi, A. Electrospun gelatin nanofibers: Optimization of genipin cross-linking to preserve fiber morphology after exposure to wáter. Acta Biomater. 2011, 7, 1702-1709. [CrossRef]

22. ASTM D1708-13. Standard test method for tensile properties of plastics by use of microtensile specimens. In Annual book of ASTM standards; American Society of Testing and Materials: Philadelphia, PA, USA, 2013.

23. Giménez, B.; Gómez-Estaca, J.; Alemán, A.; Gómez-Guillén, M.C.; Montero, M.P. Physico-chemical and film forming properties of giant squid (Dosidicus gigas) gelatin. Food Hydrocoll. 2009, 23, 585-592. [CrossRef]

24. Santos, J.P.; Esquerdo, V.M.; Moura, C.M.; Pinto, L.A.A. Crosslinking agents effect on gelatins from carp and tilapia skins and in their biopolymeric films. Colloid Surf. A-Physicochem. Eng. Asp. 2018, 539, 184-191. [CrossRef]

25. Li, H.; Liu, B.L.; Gao, L.Z.; Chen, H.L. Studies on bullfrog skin collagen. Food Chem. 2004, 84, 65-69. [CrossRef]

26. Coppola, M.; Djabourov, M.; Ferrand, M. Unified phase diagram of gelatin films plasticized by hydrogen bonded liquids. Polymer 2012, 53, 1483-1493. [CrossRef]

27. Duconseille, A.; Wien, F.; Audonnet, F.; Traore, A.; Refregiers, M.; Astruc, T.; Santé-Lhoutellier, V. The effect of origin if the gelatin and ageing on the secondary structure and water dissolution. Food Hydrocoll. 2017, 66, 378-388. [CrossRef]

28. Liu, H.; Li, D.; Guo, S. Rheological properties of channel catfish (Ictalurus punctaus) gelatine from fish skins preserved by different methods. LWT-Food Sci. Technol. 2008, 41, 414-419. [CrossRef]

29. Etxabide, A.; Urdanpilleta, M.; Guerrero, P.; de la Caba, K. Effects of cross-linking in nanostructure and physicochemical properties of fish gelatins for bio-applications. React. Funct. Polym. 2015, 94, 55-62. [CrossRef]

30. Uranga, J.; Puertas, A.I.; Etxabide, A.; Dueñas, M.T.; Guerrero, P.; de la Caba, K. Citric acid-incorporated fish gelatin/chitosan composite films. Food Hydrocoll. 2019, 86, 95-103. [CrossRef]

31. Devi, A.F.; Buckow, R.; Singh, T.; Hemar, Y.; Kasapis, S. Colour change and proteolysis of skim milk during high pressure thermal-processing. J. Food Eng. 2015, 147, 102-111. [CrossRef]

32. Kim, J.S.; Lee, Y.S. Effect of reaction $\mathrm{pH}$ on enolization and racemization reactions of glucose and fructose on heating with amino acid enantiomers and formation of melanoidins as result of the Maillard reaction. Food Chem. 2008, 108, 582-592. [CrossRef]

33. Garrido, T.; Leceta, I.; Cabezudo, S.; Guerrero, P.; de la Caba, K. Tailoring soy protein film properties by selecting casting or compression as processing methods. Eur. Polym. J. 2016, 85, 499-507. [CrossRef]

34. Nur Hanani, Z.A.; Cheng, F.Y.; Nor-Khaizura, M.A.R. Effect of pomegranate (Punica granatum L.) peel powder on the antioxidant and antimicrobial properties of fish gelatin films as active packaging. Food Hydrocoll. 2019, 89, 253-259. [CrossRef]

35. Hazaveh, P.; Nafchi, A.M.; Abbaspour, H. The effects of sugars on moisture sorption isotherm and functional properties of cold water fish gelatin films. Int. J. Biol. Macromol. 2015, 79, 370-376. [CrossRef]

36. Hoque, M.S.; Benjakul, S.; Prodpran, T. Properties of film from cuttlefish (Sepia pharaonis) skin gelatin incorporated with cinnamon, clove and star anise extracts. Food Hydrocoll. 2011, 25, 1085-1097. [CrossRef]

(C) 2020 by the authors. Licensee MDPI, Basel, Switzerland. This article is an open access article distributed under the terms and conditions of the Creative Commons Attribution (CC BY) license (http://creativecommons.org/licenses/by/4.0/). 